\title{
Expressive writing during the COVID-19 pandemic: themes of mixed expressive writing
}

\author{
Hao Yue Tay ${ }^{1}$, Chengen Yu ${ }^{1}$, Chen Sung Wong ${ }^{1}$, Kususanto Ditto Prihadi ${ }^{2}$ \\ ${ }^{1}$ Department of Psychology, Faculty of Behavioral Sciences, Education and Languages, HELP University, Kuala Lumpur, Malaysia \\ ${ }^{2}$ Faculty of Social Science and Liberal Arts, UCSI University, Kuala Lumpur, Malaysia
}

\begin{tabular}{l}
\hline Article Info \\
\hline Article history: \\
Received Aug 29, 2021 \\
Revised Nov 8, 2021 \\
Accepted Nov 19, 2021 \\
\hline
\end{tabular}

Keywords:

Expressive writing

Psychological constructs

Thematic analysis

Themes

\begin{abstract}
In order to curb the depression levels among youth during the coronavirus disease 2019 (COVID-19) outbreak, we examined the recurrent themes of mixed expressive writing among undergraduates during the pandemic. Previous quantitative studies had emphasized on the effectiveness of expressive writing in reducing depressive symptoms, however, less qualitative studies were conducted in evaluating the content within people's writings. As the pandemic had caused major disruptions among people, we implemented mixed expressive writing in capturing both positive and negative experiences during the pandemic. Ten participants were recruited to perform mixed expressive writing twice per week, for four consecutive weeks. Thematic analysis was used in analyzing their writings and forming the emerged themes. Five themes were formed, which included 'school', 'relationships', 'reflection', 'work', and 'random incidents'. Future research should examine the effectiveness of expressive writing in writing specific themes on improving its respective psychological constructs.
\end{abstract}

This is an open access article under the $\underline{C C B Y-S A}$ license.

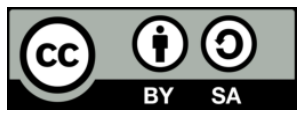

\section{Corresponding Author:}

Hao Yue Tay

Department of Psychology, Faculty of Behavioral Sciences, Education and Languages, HELP University

Damansara, Kuala Lumpur, 50490, Malaysia

Email: thyhyue@gmail.com

\section{INTRODUCTION}

This qualitative study aimed to explore the recurrent themes of mixed expressive writing among undergraduates during the coronavirus disease 2019 (COVID-19) pandemic among adults in Malaysia. Expressive writing was designed to help people with traumatic experiences to decrease the negative effects such as stress and anxiety through translating their past experiences into language [1]. Expressing their deepest thoughts and feelings allows them to review and reflect on the past experiences, which helped them confront traumatic events by reconstructing them in a meaningful way [2]. It was suggested as an effective intervention for aiding populations with stress-related illness [3], [4]. Moreover, it is also a simple, inexpensive, and convenient method that has been broadly utilized and applied for multiple purposes like emotional adjustment [5], anxiety reduction [6], and professional therapy sessions [7].

Most of the studies on expressive writing were conducted quantitatively, focusing on evaluating the effectiveness in reducing depressive symptoms [8]-[10]. Less attention was emphasized on qualitative studies that focus on the content of the writings, as past qualitative studies tend to focus on the recurrent themes of specific topics. For example, a qualitative study by Bremault-Phillips et al. [11] examined the challenging experiences among pregnant and pre-conception women and their resilience practices through expressive writing, whereby themes such as 'fears', 'relationships', and 'trauma' were reported regarding their challenging situations, while themes of 'practices and strategies' as well as 'resilience characteristics' were reported regarding their strategies for resilience. Another qualitative study by Russell [12] focused on aiding college students in overcoming obstacles during their study through expressive writing, in which the 
participants reported a release from emotional tension, recognition of personal accomplishment, positive feelings regarding the future, better control over the upsetting circumstance, and improve understanding of their past experiences in overcoming the obstacles. These studies provided information and themes about a specific topic, as participants were asked to write about topics such as challenges regarding tragedy [11] and academic obstacles [12] during the writing process. In this current study, we attempt to fill in the gap by examining the emerged themes within participants' writing content without specifying any writing topics. It was expected that we would be able to disclose the deeper thoughts among our participants, who happened to be living under the enforcement of movement control order (partial lockdown) amidst the pandemic.

The pandemic is an influential environmental factor that might cause an overall stressful and depressing situation [13]. Moreover, it is followed by the enforcement of social distancing rules, such as working from home, locked down, and closing of certain businesses, that led to interpersonal, occupational, and financial strain [14]. These disruptions could trigger negative emotions such as hopelessness and loneliness that ultimately contribute to high rates of anxiety and depression [15]. It was reported that expressive writing was effective in reducing depression symptoms during the pandemic situation [16], especially among participants who were instructed to write positive experiences [10]. Nevertheless, no report has been made on the content of the participants' writing. In order to fill the gap, we conduct this current qualitative study where participants were required to include both positive and negative experiences in their writings. It is expected that by analyzing the writing qualitatively, we would be able to capture the content of the participants' mind during the pandemic situation. In order to obtain more holistic thoughts of our participants, they were instructed to write both positive and negative experience.

\section{RESEARCH METHOD}

\subsection{Participants}

Ten young adults (five males, five females) aged between 21 to 27 years old were recruited through online research advertisements. The participants were not being diagnosed with any psychological disorder and did not participate in any counselling or psychotherapy sessions. They were awarded with a RM5 Grab credit voucher for the completion of the writings at the end of each week.

\subsection{Procedure}

Participants engaged in expressive writing twice per week, specifically one writing on Tuesdays while the other one on Fridays. During each session, participants received the following instruction, "For the following writing sessions, we would like you to write about any past experience that comes to your mind. Please include both positive and negative experiences in your writing. Write about the experience in as much detail as possible trying to include the feelings, thoughts, and emotions that were present at the time." This method was conducted in four consecutive weeks. Participants were given 48 hours to complete each writing and submitted it through Google Form.

\subsection{Analysis}

Grounded theory procedure by Strauss and Corbin [17] was conducted in the first round of data analysis, where we implemented open coding to extract information from these writings, followed by thematic analysis with axial coding to reassemble similar concepts in forming its respective themes. The analysis process is listed in Table 1.

Table 1. The analysis process

\begin{tabular}{|c|c|c|c|}
\hline Participants & Week & Writing excerpts & Themes/Sub-themes \\
\hline 2 & 2B & $\begin{array}{l}\text { The negative experience I had was I could not achieve the top } 10 \text { performance } \\
\text { for chemistry subject in UEC exam during my form } 6 \text {. It was heart breaking as I } \\
\text { invested a lot of my time and effort into chemistry and I thought I could do it. } \\
\text { But end up I perform quite bad during the exam because of exhaustion. But the } \\
\text { process of achieving this goal is happy and I felt satisfying. The moment of } \\
\text { putting effort in studying it and doing exercise on it is fun. }\end{array}$ & $\begin{array}{l}\text { School/Academic } \\
\text { achievements }\end{array}$ \\
\hline 2 & $4 \mathrm{~A}$ & $\begin{array}{l}\text { I'm so excited to eat the new menu of subway and I'm thinking of how I } \\
\text { can get the best deal to save money but satisfy my desire. I thought of an } \\
\text { idea to share the sandwich with my sis but she could not understand what I } \\
\text { am saying and wanted a different sandwich with mine. I'm sad that I could } \\
\text { not eat as much flavour as i wan. }\end{array}$ & Random incident \\
\hline 11 & $4 \mathrm{~A}$ & $\begin{array}{l}\text { Well, this is a new week. The glad issue is that client has submitted those } \\
\text { requested document, however another issue is that I have to solve some } \\
\text { problem. A sad issue is that all of my work (previously done) has } \\
\text { disappeared, so I have to redo again. However it's still lucky because I still } \\
\text { manage to complete them within half day. Besides, I'm happy because my } \\
\text { senior taught me to do another task rather than just a repetition task. }\end{array}$ & Work \\
\hline
\end{tabular}

Int J Public Health Sci, Vol. 11, No. 1, March 2022: 195-203 


\section{RESULTS AND DISCUSSION}

In the following subsections, results were discussed. The results were identified as themes representing the content of participants' expressive writings. Five themes were formed based on our analysis through the text written by our participants. These included school, relationships, reflections, work, and random incidents.

\subsection{School}

Participants who wrote about the 'school' theme mentioned their experiences in high school or university, either in the past or during the present time. Under this theme, two sub-themes were formed, which were 'school events' and 'academic achievement'. In the sub-theme 'school events', participants described their school incidents, especially club activities that they organized while having the abilities in managing the events:

"I remember the day of the talent show our club organised in university... I was in charge of backstage, and was really excited to meet the participants...The show went well, and I was happy to meet different participants of different talents. It was really hectic, and from time to time frustrated because there was unexpected stuff happening, but everything went smoothly and I was really satisfied with how our team performed." (Participant 1, Week 3A)

This may reflect on their high self-efficacy, which they strongly believed in themselves having potential to manage the events smoothly, as mentioned in the self-efficacy theory [18]. Self-efficacy refers to the beliefs in one's capabilities to produce appropriate actions in managing prospective situations. In line with that, a study by Bekomson et al. [19] suggested that extra-curricular activities positively relate to selfefficacy, as when students involved in extra-curricular activities, they were exposed to challenging situations that provided them opportunities to develop characters such as self-efficacy, perseverance, and locus of control.

Accordingly, Bandura [20] also suggested that the most efficient way in building one's self-efficacy is through the mastery of subjects while failures hinder the process. Extra-curricular activities often allow room for mistakes, which provides a perfect environment for students to master specific skills without afraid of failing and eventually develop one's self-efficacy. Therefore, participants who wrote about school events might exhibit higher self-efficacy, as they perceived themselves as capable in taking care of difficult situations especially in their extra-curricular activities.

In the sub-theme 'academic achievement', participants mentioned about the experiences with their academic work, which often paired with their strategies in overcoming the obstacles to achieve better results:

"I remember completing my last paper for finals for my degree. I was in my room alone working on my online test, which looks not as tough to me at first glance, but as the perfectionist $i$ am, $i$ told myself $i$ need to take as much time as $i$ can to complete this so i don't regret anything. $i$ contacted some friends for help and to discuss on some tougher questions. I was really stressed because it was my last ever paper and $i$ want to get a good grade for it, but at the same time $i$ was also relieved thinking about the end of my degree after $i$ finish this paper." (Participant 1, Week 1B)

"One of my past experience come to my mind is my first e-Exam. That was before COVID-19 and was around 2019. I was very nervous before the exam although that I have prepared for the exam a few weeks ago. The main reason that I am anxious is because I have heard that the failing rate of this unit that I am sitting for is very high, and also that was my very first physical e-Exam. At the start of the exam I was quite nervous as well but after answering the first few questions, I was able to focus and ignore any feelings." (Participants 7, Week 3A)

Self-efficacy could be also seen in these writings, as participants believed in themselves to overcome any obstacles in their academic work. While past studies often indicated the directional relationship of self-efficacy in predicting academic achievements [21], [22]. Hwang et al. [23] found that academic achievement positively predicted self-efficacy, as when students reflect on their academic achievements, this promotes the understanding of their inner strengths and abilities, which could predict selfefficacy in the future. This could raise their confidence level in getting better academic achievement in the future and eventually creates an upward spiral. With that mentioned, we concluded that our participants who wrote about academic achievements might predict future increases in self-efficacy, in which they recognized their capabilities and improved their confidence level. 


\subsection{Relationships}

Under this theme, three sub-themes were formed which were 'family relationship', 'romantic relationship', and 'friendship'. Participants showed gratefulness when they mentioned about the relationships with their family members:

"Spending it (Chinese New Year) with my grandmother and cousins, I feel very thankful that we were still able to have a good time...time to bond with loved ones, a good and able body, these are ultimate treasures." (Participant 14, Week 1B) loved ones:

In the sub-theme of 'romantic relationship', participants tend to describe the experiences with their

“...the experience of my first love, I was having a lot of nice and fun moment with her, and all the sweet memories. But the experience of broke up was heart breaking. I cost a lot of pain to me and I was so upset every day." (Participant 2, Week 1B)

In the sub-theme of 'friendship', participants often describe certain incidents and how it influenced their friendship:

"At the same time also feeling lucky to have a friend that can understand me and listen to me when I was feeling upset. I was grateful and feeling better when I can express all the shitty things to someone that stand on my side. Tell myself to focus on correct and better future instead of being overwhelmed by negative emotions." (Participant 6, Week 1A)

Participants' writings on relationships often reflect on the nostalgic feelings of missing someone important in their lives, either a family member, romantic partner, or a friend. However, these writings were also paired with the expression of gratitude, in which participants cherished the moments that they had gone through with their significant ones. This could be seen in Butler and Jaffe [24] study, where Microsoft software engineers were asked to write down things to be grateful for during the experience of working from home, the decreasing need for travel, having their family around, as well as having supportive teams and great management were commonly reported in their diaries.

Similarly, participants in Lefdahl-Davis et al. [25] study also reported having strong ability to be aware of the things that happened and express their gratitude especially to people around them during the pandemic. This could be due to them realizing the importance of social relationships, as Waters et al. [26] mentioned that the pandemic had threatened the routines and beliefs that we adhered to in the past, meaningful relationships and activities in our lives, as well as the goals and plans for the future. When social activities were restricted and people were required to adhere to physical distancing during the pandemic, it had caused disruptions to their relationships. With that saying, this might lead our participants to be more likely to feel grateful for the past moments with their loved ones which they took for granted, as by expressing gratitude, it strengthens the relationships with our significant ones [27]. Therefore, participants who wrote about relationships in their expressive writing might feel a sense of gratitude for the experiences that had been made together with others especially during the pandemic.

\subsection{Reflection}

There were also participants that engaged in reflective thinking when writing their content, which revealed their inner thoughts and feelings around their experiences. There are three sub-themes under this theme: 'self-understanding', 'regretting', as well as 'development and improvement'. In the sub-theme of 'self-understanding', participants tend to write about what had happened and their feelings which led them in building an impression of themselves:

"When I failed university, I was so sad with myself. I was thinking that I was lacking because why could others do it and I can't. I felt disappointed with myself and I felt lost, not knowing what to do with my life." (Participant 14, Week 2A)

In the sub-theme of 'regretting', participants mentioned about their past mistakes and failures while regretted on their behaviors at that moment:

"The experience ... is my last performance during my foundation... Some of the negative experiences were the mistake that I made during the show that makes me regret as I would think 'I could do it better." (Participant 7, Week 1B)

Int J Public Health Sci, Vol. 11, No. 1, March 2022: 195-203 
In the sub-theme of 'development and improvement', participants reflected on their past experiences to examine how much they had grown and what they wish to become in the future:

“...I'm going to talk about my friendships. Honestly, I feel that my circle of friends is quite small. I have 2 to 3 close friends, and by the term 'close friend', I mean those who I trust enough to confide in...My past experiences have taught me to protect my feelings. Therefore, I keep everything to myself since ever. I rarely make a commitment to the friendships, not to mention sharing my secrets or the deepest thoughts. I write my thoughts on a book whenever I feel overwhelmed... Occasionally, I feel myself not that sincere, though.” (Participant 16, Week 2A)

Interestingly, although our instructions did not require participants in reflecting their past experiences, many participants still chose to do so. This indicated that when participants were involved in expressive writing, it could induce a need for reflection among participants. These writings were often expressed in a negative tone, which might manifest the expression of rumination on their past failures, regrets, and being desperate to improve themselves. This could be in line with Newman and Nezlek [28] study, which suggested that reflection was negatively correlated with well-being, as the act of reflection tends to be ruminative in nature [29], which leads people to reinforce their negative thoughts about themselves. Thereby, we suggested that our participants who reflected on their past experiences tend to view themselves as having negative qualities, which could negatively impact their well-being.

\subsection{Work}

Under this part, participants mentioned their job-related experiences, which include the work incidents and social relationships in the workplace. Majority of them described about the difficulties that they encountered during work, which often triggers negative emotions:

"...because initially I thought my main work has been completed, and finally can say a yay and feel the sense of completeness....During the small team follow up meeting at the end of the Tuesday, it was discovered that there are still work undone!...Therefore, the stress came back, and all the happiness after completing previous task all gone." (Participant 11, Week 1A)

"Felt angry and exasperated when I was doing my internship because I felt like I did not have enough time to do what I want outside of work. "Do we have to work eight hours every day in the office?" was what I thought to myself. I wished we only have to work six hours a day and have the freedom to space it out as we like. Taking naps in between if we want to." (Participant 14, Week 3B)

One of the experience comes to my mind is my first internship experience...I was the only internship in the office and I am not really good in socialising, so I was eating lunch with the Chinese colleague that sits right beside me, but after he leave to another department, I was eating lunch alone for a few weeks until my supervisor invited me to have lunch with her and her friends together...It was overall a positive experience, although I didn't really gain any useful experience but I manage to earn a letter of appreciation and some soft skills through this internship period." (Participant 7, Week 4A)

As stated above, participants who wrote about their work-related experiences tend to express a sense of dissatisfaction with their job. They perceived their job experiences as hectic, repetitive, and less meaningful (Participant 7), while some participants described their inability in achieving work life balance (Participant 14), which had caused them to be less indulged with the job. Lee et al. [30] reported that employees' positive experiences in work life positively predicts one's life satisfaction especially when they faced less work-family life conflicts, which indicated that employees heavily emphasized on achieving work life balance in their jobs. This could be clearly seen in Mos [31] study, where employees mentioned their commitment in managing their time to achieve the balance between work and family.

Another recent study by Butler and Jaffe [24] also mentioned that common challenges such as the feeling of being overworked, the struggle in maintaining mental and physical health, as well as the inability in achieving work life balance had affected the participants to feel less satisfied with their daily life. Thereby, we concluded that participants who wrote about work-related experiences tend to express their negative job experiences, which might negatively predict one's life satisfaction.

\subsection{Random incident}

In this theme, most of the contents heavily revolved around their daily life experiences. Some participants mentioned about their special occasions: 
"I remembered when I knew I was selected for National Service I felt so devastated because I didn't want to go for it although it is compulsory...I was so homesick for the first two weeks but was glad to knew good friends and started to enjoy it." (Participant 9, Week 2B)

In other writings the participants recorded unexpected events:

"I was involved in a car accident last week... When it happened; I was like oh god I screwed up... I was lucky. Had the car not swerved, it would have gone right at me and I would have been injured badly or died... I did not have responsibilities that would be seriously affected due to the accident. I had no money problem as I can claim insurance." (Participant 14, Week 4A)

However, in most of the writings, participants briefly described what happened in their daily life:

"I went for a walk/hike into the hill near my home. Felt amazing being in nature and putting in the work for my body. Felt determined to put in the work everyday to be healthy. Thought to myself I am so proud of who I have become." (Participant 14, Week 3B)

As this theme contained contents that were varied in its nature, we could not propose any connections between this themes with the other psychological constructs. However, this theme still provided us an insight that participants who engaged in expressive writing were not limited in writing things about their school, relationship, reflection, and work; they could also express these random experiences that happened in their lives.

Five themes were formed in this study, ranging from 'school', 'relationships', 'reflection', 'work', to 'random incident' and some possible connections between these themes and its respective psychological constructs were proposed. Firstly, writing about school events might represent higher sense of self-efficacy, while writing about academic achievements might represent hope and/or improvement in self-efficacy. Writing about relationships tends to be linked to the expressions of gratitude for the past experiences with their loved ones especially during the pandemic. Other than that, further studies are suffested for participants who reflected on their past experiences as having negative qualities, which could negatively impact their well-being. Lastly, participants who wrote about work tend to express their negative job experiences, which might negatively have linked to life satisfaction. The aforementioned themes seem to have represented the content of the thoughts expressed in the writing

Past qualitative studies had focused on the effectiveness of expressive writing in reducing one's negative emotions and symptoms [12], [32]. However, fewer studies had examined the recurring themes from the writings and its latent connection with various psychological constructs. Hence, this study filled in this gap by understanding the content in participants' writings, while proposing the possible connections between themes and its respective psychological construct. This may allow future studies in expressive writing to not only evaluate the content but also investigate the effectiveness of expressive writing in affecting one's selfefficacy, gratitude, well-being, and life satisfaction. As expressively writing positive experiences was considered as an effective way to reduce anxiety and depression [10], [33], it is proposed that the themes disclosed in this study can be suggested to be written daily for individuals during the pandemic to protect them from having symptoms for anxiety and depression.

\section{CONCLUSION}

This paper examined the recurrent themes within participants' mixed expressive writing during the pandemic. Five themes were formed and future studies should broaden the scope by including individuals in a wider population and utilize interviews in comprehending the participants' content. Quantitative method is also suggested in examining the effectiveness of expressive writing in writing specific themes on improving its respective psychological constructs.

This study has several limitations. One limitation in this study was that we could not access the participants' underlying reasons in writing specific themes by merely analyzing their writings. These reasons, or in another word, their original intentions might have an influence on our predicted themes. For example, if one wrote about his/her past experiences with a friend and reviewed his/her mistakes in this relationship, we would classify this under the sub-theme of 'friendship'. However, if his/her initial intention in writing this was a reflection process, which this experience had successfully helped him to realize the importance and preciousness of friendship, then it should be more suitable to classify under the theme of 'Reflection'. Since participants' intention of writing about certain experiences can not be examined from the content, this may cause some faulty analysis of the themes.

Int J Public Health Sci, Vol. 11, No. 1, March 2022: 195-203 
The second limitation was that although we had asked participants to include their feelings and emotions in the expressive writing, we still could not be sure whether they had fully expressed their emotions during the writing process. Participants' emotions when writing about certain themes might influence the direction of our proposed psychological constructs. Future studies could investigate the roles of participants' emotions during the writing process in affecting the relationship of its respective psychological constructs by utilizing both documentation and interview. Third, our sample only included undergraduate students, where the recurrent themes were limited to support these individuals. It suggested that future studies should include a more diverse group as their sample when evaluating the themes to better understand the primary objects across a wider population, which also allows the comparison of themes in the future.

\section{ACKNOWLEDGEMENTS}

This study is funded by internal research grant (IRGS\#21-01-001) from Research Management Center of HELP University.

\section{REFERENCES}

[1] J. W. Pennebaker, "Expressive writing in psychological science," Perspectives on Psychological Science, vol. 13, no. 2, pp. 226229, Mar. 2018, doi: 10.1177/1745691617707315.

[2] C. S. Pulverman, R. L. Boyd, A. M. Stanton, and C. M. Meston, "Changes in the sexual self-schema of women with a history of childhood sexual abuse following expressive writing treatment," Psychological Trauma: Theory, Research, Practice, and Policy, vol. 9, no. 2, pp. 181-188, Mar. 2017, doi: 10.1037/tra0000163.

[3] S. Ayers et al., "Evaluation of expressive writing for postpartum health: a randomised controlled trial," Journal of Behavioral Medicine, vol. 41, no. 5, pp. 614-626, Oct. 2018, doi: 10.1007/s10865-018-9970-3

[4] S. Rabiepoor, N. Vatankhah-Alamdary, and H. R. Khalkhali, "The effect of expressive writing on postpartum depression and stress of mothers with a preterm infant in NICU," Journal of Clinical Psychology in Medical Settings, vol. 27, no. 4, pp. 867-874, Dec. 2020, doi: 10.1007/s10880-019-09688-2.

[5] E. M. P. Dewi, A. Ridfah, and Usrayanti, "The effectiveness of expressive writing therapy in controlling emotions of adolescent inmate," in Proceedings of the 3rd International Conference on Education, Science, and Technology (ICEST 2019), 2020, pp. 4549, doi: 10.2991/assehr.k.201027.009.

[6] Y. Tang and L. Ryan, "Music performance anxiety: Can expressive writing intervention help?," Frontiers in Psychology, vol. 11, Jun. 2020, doi: 10.3389/fpsyg.2020.01334.

[7] O. Glass, M. Dreusicke, J. Evans, E. Bechard, and R. Q. Wolever, "Expressive writing to improve resilience to trauma: A clinical feasibility trial," Complementary Therapies in Clinical Practice, vol. 34, pp. 240-246, Feb. 2019, doi: 10.1016/j.ctcp.2018.12.005.

[8] S. W. Lee, I. Kim, J. Yoo, S. Park, B. Jeong, and M. Cha, "Insights from an expressive writing intervention on Facebook to help alleviate depressive symptoms," Computers in Human Behavior, vol. 62, pp. 613-619, Sep. 2016, doi: 10.1016/j.chb.2016.04.034.

[9] M. Fartoukh and L. Chanquoy, "Expressive writing in school children: effects on well-being and working memory," Journal of Writing Research, vol. 11, no. 3, pp. 505-523, Feb. 2020, doi: 10.17239/JOWR-2020.11.03.04.

[10] C. S. Wong, M. J. Chua, and K. D. Prihadi, "Reducing depressive symptoms and increasing positive feelings with expressive writing," International Journal of Public Health Science (IJPHS), vol. 10, no. 2, pp. 433-444, Jun. 2021, doi: 10.11591/ijphs.v10i2.20797.

[11] S. Brémault-Phillips, A. Pike, J. Olson, E. Severson, and D. Olson, "Expressive writing for wildfire-affected pregnant women: Themes of challenge and resilience," International Journal of Disaster Risk Reduction, vol. 50, p. 101730, Nov. 2020, doi: 10.1016/j.ijdrr.2020.101730.

[12] J. A. Russell, "Expressive writing and community college students: making meaning of their experiences in life and academics," American Association for Adult and Continuing, pp. 204-210, 2021.

[13] C. Wang et al., "Immediate psychological responses and associated factors during the initial stage of the 2019 coronavirus disease (COVID-19) epidemic among the general population in China," International Journal of Environmental Research and Public Health, vol. 17, no. 5, pp. 1-25, Mar. 2020, doi: 10.3390/ijerph17051729.

[14] A. Kujawa, H. Green, B. E. Compas, L. Dickey, and S. Pegg, "Exposure to COVID-19 pandemic stress: Associations with depression and anxiety in emerging adults in the United States," Depression and Anxiety, vol. 37, no. 12, pp. 1280-1288, Dec. 2020, doi: 10.1002/da.23109.

[15] T. Elmer, K. Mepham, and C. Stadtfeld, "Students under lockdown: comparisons of students' social networks and mental health before and during the COVID-19 crisis in Switzerland," PLOS ONE, vol. 15, no. 7, pp. 1-22, Jul. 2020, doi: 10.1371/journal.pone.0236337.

[16] R. Procaccia, G. Segre, G. Tamanza, and G. M. Manzoni, "Benefits of expressive writing on healthcare workers' psychological adjustment during the COVID-19 pandemic," Frontiers in Psychology, vol. 12, pp. 1-10, Feb. 2021, doi: 10.3389/fpsyg.2021.624176.

[17] J. C. Anselm Strauss, Juliet M. Corbin, Basics of qualitative research: Techniques and procedures for developing grounded theory. California: SAGE Publications, 1998.

[18] A. Bandura, "Self-efficacy: Toward a unifying theory of behavioral change," Psychological Review, vol. 84, no. 2, pp. 191-215, 1977, doi: 10.1037/0033-295X.84.2.191.

[19] A. N. Bekomson, M. N. Amalu, A. N. Mgban, and K. B. Abang, "Interest in extra curricular activities and self efficacy of senior secondary school students in cross river state, Nigeria," International Education Studies, vol. 13, no. 8, p. 79, Jul. 2020, doi: 10.5539/ies.v13n8p79.

[20] A. Bandura, "Self-efficacy," in The Corsini Encyclopedia of Psychology, Volume 4, W. E. C. Irving B. Weiner, Ed. New Jersey: John Wiley \& Sons, 2010.

[21] F. Doménech-Betoret, L. Abellán-Roselló, and A. Gómez-Artiga, "Self-efficacy, satisfaction, and academic achievement: the mediator role of students' expectancy-value beliefs," Frontiers in Psychology, vol. 8, pp. 1-12, Jul. 2017, doi: 
10.3389/fpsyg.2017.01193.

[22] J. Roick and T. Ringeisen, "Self-efficacy, test anxiety, and academic success: a longitudinal validation," International Journal of Educational Research, vol. 83, pp. 84-93, 2017, doi: 10.1016/j.ijer.2016.12.006.

[23] M. H. Hwang, H. C. Choi, A. Lee, J. D. Culver, and B. Hutchison, "The relationship between self-efficacy and academic achievement: A 5-year panel analysis," Asia-Pacific Education Researcher, vol. 25, no. 1, pp. 89-98, Feb. 2016, doi: 10.1007/s40299-015-0236-3.

[24] J. Butler and S. Jaffe, "Challenges and gratitude: a diary study of software engineers working from home during COVID-19 Pandemic," in Proceedings - International Conference on Software Engineering, 2021, pp. 362-363, doi: 10.1109/ICSESEIP52600.2021.00047.

[25] E. M. L.- Davis, D. Stefan, L. Huffman, and A. Alayan, "Positive psychology during a pandemic: reframe for well-being," European Journal of Applied Positive Psychology, vol. 4, pp. 1-15, 2020.

[26] L. Waters et al., "Positive psychology in a pandemic: buffering, bolstering, and building mental health," Journal of Positive Psychology, pp. 1-21, Feb. 2021, doi: 10.1080/17439760.2021.1871945.

[27] S. B. Algoe, "Positive interpersonal processes," Current Directions in Psychological Science, vol. 28, no. 2, pp. 183-188, Apr. 2019, doi: $10.1177 / 0963721419827272$.

[28] D. B. Newman and J. B. Nezlek, "Private self-consciousness in daily life: relationships between rumination and reflection and well-being, and meaning in daily life," Personality and Individual Differences, vol. 136, pp. 184-189, Jan. 2019, doi: 10.1016/j.paid.2017.06.039.

[29] D. Stein and A. M. Grant, "Disentangling the relationships among self-reflection, insight, and subjective well-being: The role of dysfunctional attitudes and core self-evaluations," Journal of Psychology: Interdisciplinary and Applied, vol. 148, no. 5, pp. 505522, Sep. 2014, doi: 10.1080/00223980.2013.810128.

[30] D. J. Lee, G. B. Yu, M. J. Sirgy, A. Singhapakdi, and L. Lucianetti, "The effects of explicit and implicit ethics institutionalization on employee life satisfaction and happiness: The mediating effects of employee experiences in work life and moderating effects of work-family life conflict," Journal of Business Ethics, vol. 147, no. 4, pp. 855-874, Feb. 2018, doi: 10.1007/s10551-015-2984-7.

[31] B. Mos et al., "Generation-Y employees and their perceptions of work-life balance," Journal of Cognitive Sciences and Human Development, vol. 4, no. 2, pp. 28-41, Dec. 2018, doi: 10.33736/jcshd.1122.2018.

[32] L. Shen, L. Yang, J. Zhang, and M. Zhang, "Benefits of expressive writing in reducing test anxiety: a randomized controlled trial in Chinese samples," PLOS ONE, vol. 13, no. 2, p. e0191779, Feb. 2018, doi: 10.1371/journal.pone.0191779.

[33] M. H. Doucet, M. Farella Guzzo, and D. Groleau, "Brief report: a qualitative evidence synthesis of the psychological processes of school-based expressive writing interventions with adolescents," Journal of Adolescence, vol. 69, pp. 113-117, Dec. 2018, doi: 10.1016/j.adolescence.2018.09.010.

\section{BIOGRAPHIES OF AUTHORS}
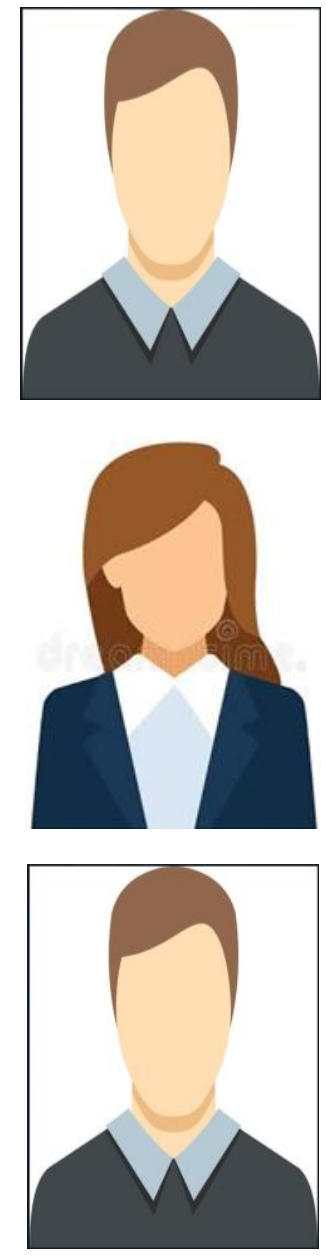

Hao Yue Tay (D) SC P is a Malaysian young student of psychology and research assistant in the Department of Psychology, Faculty of Behavioral Science, HELP University Malaysia. He can be contacted at email: fosslaresearch@gmail.com.

Chengen Yu (D) If SC P is a Chinese national, who is currently studying psychology and assisting research in the Department of Psychology, Faculty of Behavioral Science, HELP University Malaysia. She can be contacted at email: fosslaresearch@gmail.com.

Chen Sung Wong (D) SC $\mathrm{P}$ is a young Malaysian psychology graduate from Department of Psychology, Faculty of Behavioral Science, HELP University Malaysia, with several researches in expressive writing. He is the main investigator of this study. Most of his papers were about improving mental health through various ways of expressive writing. He can be contacted at email: fosslaresearch@gmail.com. 


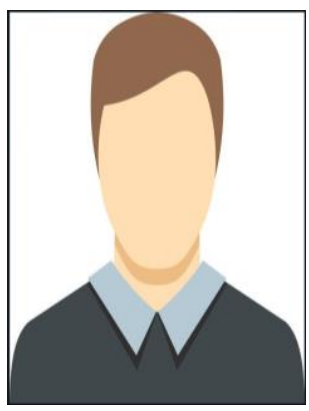

Kususanto Ditto Prihadi (D) SC P is an Indonesian national who holds a doctorate in Educational Psychology with deep research interest in psychology of mattering and self, he co-leads this current study. Most of his papers in the last two years were related to role of mattering on mental health and people's wellbeing. He is currently the Head of Research and Postgraduate Studies in the Faculty of Social Science and Liberal Arts, UCSI

University Malaysia. He can be contacted at email: fosslaresearch@gmail.com. 